\title{
ANALYSIS OF THE IMMUNE RESPONSE OF CALVES TO VARIOUS SAPONIN-BASED ADJUVANTS FOR AN EXPERIMENTAL MYCOPLASMA BOVIS VACCINE
}

\author{
Katarzyna DudeK ${ }^{1 *}$, Dariusz BedNAREK ${ }^{1}$, Roger D. AYLING ${ }^{3}$, Maria SzCZOTKA ${ }^{2}$, \\ Ewelina IWAN $^{2}$ and Janusz KoCKI ${ }^{4}$ \\ ${ }^{1}$ Department of Cattle and Sheep Diseases and ${ }^{2}$ Department of Biochemistry, \\ National Veterinary Research Institute, 57 Partyzantów Avenue, 24-100 Puławy, Poland; \\ ${ }^{3}$ Mycoplasma Team, Animal and Plant Health Agency (Weybridge), Addlestone, Surrey, \\ UK; ${ }^{4}$ Department of Clinical Genetics, Medical University of Lublin, Lublin, Poland
}

(Received 16 February 2018; accepted 16 April 2016)

\begin{abstract}
Mycoplasma bovis is a primary infectious agent of many disorders in cattle including bovine respiratory disease. No commercial vaccines against $M$. bovis are available in Europe. The immune response of calves to three saponin-based adjuvants combined with a field Polish $M$. bovis strain was evaluated. Four groups of six calves each were injected subcutaneously with the M. bovis strain combined with either saponin, saponin + Emulsigen $^{\circledR}$, saponin + Emulsigen $^{\circledR}+$ alphatocopherol acetate, or with phosphate-buffered saline as control group. Blood and nasal swab samples were collected up to day 84 post injection. All formulations effectively stimulated the humoral and the cellular immune response of the calves, but the course of the response depended on the adjuvant formulation. These immunological data provide additional information supporting the findings of previous $M$. bovis saponin and Emulsigen ${ }^{\circledR}$ vaccine challenge studies to facilitate the development of successful $M$. bovis vaccines.
\end{abstract}

Key words: Mycoplasma bovis, cattle, saponin, Emulsigen ${ }^{\circledR}$, DL-alphatocopherol acetate

Mycoplasma bovis is an infectious agent of cattle causing bronchopneumonia, arthritis and mastitis (Nicholas and Ayling, 2003). It is still widespread in Poland, causing economic losses and adversely affecting animal health and welfare (Szacawa et al., 2015). Currently no commercial vaccines against $M$. bovis are available in Europe. However, in some experimental studies treatment with a saponin-based bacterin vaccine increased $M$. bovis-specific antibodies and protected against a $M$. bovis challenge in young calves (Nicholas et al., 2002; Dudek et al., 2016). The efficacy of a vaccine requires a stimulation of the correct protective host immune response which depends on the antigenic properties of the

*Corresponding author; E-mail: katarzyna.dudek@piwet.pulawy.pl; Phone: 0048 (81) 889-3021; Fax: 0048 (81) 886-2595 
mycoplasma isolate and the adjuvant used. Previously some vaccine studies have shown a stimulatory effect on humoral immunity but this was often not correlated with the prevention of $M$. bovis infection, disease, or colonisation of the upper and lower respiratory tract (Maunsell et al., 2009; Soehnlen et al., 2011). Considering the divergent reports it has been speculated that the cell-mediated immunity is necessary to destroy infected cells, and it is likely to be more effective in the elimination of $M$. bovis from the host than the humoral response (Nicholas et al., 2017). Information on the course of cellular immune response to M. bovis in young calves is limited. It was previously reported that the recall immune response to $M$. bovis lung infection was skewed towards the type 2 T-helper lymphocyte cytokine production (Vanden Bush and Rosenbusch, 2003). Immunisation with M. bovis vaccine showed some cytokine stimulation; however, the results obtained by different investigators remain ambiguous (Soehnlen et al., 2011; Zhang et al., 2014). The adjuvant DL-alpha-tocopheryl-acetate was included as part of this study as it is used successfully in some viral, bacterial and Mycoplasma hyopneumoniae vaccines.

An understanding of the host immune response and the immunostimulating effect of antigens with different adjuvants is essential to help formulate an effective vaccine. Here we investigated the course of the immune response of calves to a $M$. bovis bacterin vaccine consisting of a saponised field Polish $M$. bovis strain on its own, in combination with Emulsigen ${ }^{\circledR}$, and combined with Emulsigen $^{\circledR}$ and DL-alpha-tocopheryl acetate.

\section{Materials and methods}

The experimental procedures and animal management protocols were carried out in accordance with the detailed unified requirements of the Local Ethics Committee on Animal Experimentation, which also meet the EU standards.

\section{Animals}

Twenty-four approximately 5-week-old clinically healthy female calves were purchased from local farms and delivered to the Institute's vivarium. After a two-week adaptive period the calves were randomly distributed into four groups of six calves, with each group housed in individual pens. They were fed milk replacer twice a day, and hay and water ad libitum. Before the study, the calves had been examined to exclude the presence of M. bovis and Pasteurellaceae species using microbiological (Barrow and Feltham, 1993; Nicholas and Baker, 1998) and serological methods. For mycoplasma identification, nasal swab samples were cultured on Eaton's broth and agar (Nicholas and Baker, 1998) and the presence of $M$. bovis was additionally excluded using the antigenic ELISA BIO K 341/2 (Bio-X Diagnostics, Belgium). The calves were also exam- 
ined for specific antibodies against $M$. bovis (indirect ELISA BIO K 260/2 manufactured by Bio-X Diagnostics, Belgium) and bovine respiratory viruses as described by Dudek et al. (2016).

\section{Suspension of M. bovis and adjuvants}

Polish M. bovis field strain BankIt 1801634 MBovis KP795974 was cultured in a final volume of $25 \mathrm{ml}$ of Eaton's medium with gentle shaking for total of four days at $37{ }^{\circ} \mathrm{C}$ with an addition of $5 \% \mathrm{CO}_{2}$ (Nicholas and Baker, 1998). Then the culture was washed twice in phosphate-buffered saline (PBS, pH 7.2) and centrifuged at $10,000 \times g$ for $40 \mathrm{~min}$. The supernatant was finally discarded and the washed mycoplasma cells were mixed with $2 \mathrm{mg} / \mathrm{ml}$ saponin (Sigma, Poole) as described previously (Nicholas et al., 2002). In the mycoplasma cellssaponin mix the final titre of mycoplasma cells was $1.0 \times 10^{8} \mathrm{CFU} / \mathrm{ml}$. For the $\mathrm{S}+\mathrm{E}$ and $\mathrm{S}+\mathrm{E}+\mathrm{T}$ groups $2 \mathrm{ml}$ of Emulsigen ${ }^{\circledR}$ (MVP Laboratories, Inc. Ralston, Nebraska, USA) was added to $5 \mathrm{ml}$ of the mycoplasma cells-saponin mix. Finally, $3 \mathrm{ml}$ of PBS ( $\mathrm{pH} 7.2$ ) was added to the $\mathrm{S}$; and $1 \mathrm{ml}$ to the $\mathrm{S}+\mathrm{E}$ adjuvant, and $1 \mathrm{ml}$ of DL-alpha-tocopheryl acetate (Merck Millipore, $500 \mathrm{mg} / \mathrm{ml}$ ) was added for the $\mathrm{S}+\mathrm{E}+\mathrm{T}$ adjuvant. A final concentration of $6.25 \times 10^{7} \mathrm{CFU} / \mathrm{ml}$ was quantified in all of the adjuvants being tested. The CFU count was calculated according to the OD quantification method described by Ayling et al. (2000) and confirmed by carrying out dilution counts according to Postgate (1969). The vaccine formulations were checked to be free of mycoplasma and bacteria contamination by culturing on Eaton's and blood agar (Nicholas et al., 2002). A final volume of $8 \mathrm{ml}$ of each mycoplasma adjuvant mix was used for each calf.

\section{Injection of calves}

Each of the six calves in the four groups were administered $8 \mathrm{ml}$ subcutaneously in the neck, as per their assigned group, with either $\mathrm{S}, \mathrm{S}+\mathrm{E}, \mathrm{S}+\mathrm{E}+\mathrm{T}$, or PBS for the control group (C).

\section{Clinical observations}

The calves were observed throughout the experimental period. Rectal temperatures, any nasal discharge and non-specific local postvaccinal reactions (oedema, pain, etc.) were recorded early every morning before feeding milk replacer and performed for days 0 to 7 at the beginning of the study, and then at weekly intervals up to day 84 post injection.

\section{Samples}

Nasal swabs and blood samples were collected daily from all calves on days 0 to 7, and then at weekly intervals up to day 84 post injection. For haema- 
tological as well as CD2,4,8 and WC4 antigen analyses the whole blood samples were collected into a 1-ml vacutainer with EDTA-K2 anticoagulant, whereas for serological analyses the whole blood samples were collected into serum separator tubes, centrifuged at $1500 \mathrm{~g}$ at $18-25^{\circ} \mathrm{C}$ for $10 \mathrm{~min}$ to obtain sera, and then stored at $-20{ }^{\circ} \mathrm{C}$ until analysed.

Mycoplasma bovis antigen

Mycoplasma bovis was detected in nasal swabs using the antigenic ELISA BIO K 341/2 (Bio-X Diagnostics, Belgium) according to the manufacturer's instructions.

Anti-Mycoplasma bovis specific antibodies

Blood samples were examined for the presence of specific antibodies to M. bovis using indirect ELISA BIO K 260/2 manufactured by Bio-X Diagnostics (Belgium) according to the manufacturer's instructions.

\section{Blood leukocyte counts}

Total white blood cell (WBC) counts with differentiation of polymorphonuclear leukocytes (GRA), lymphocytes (LYM) and monocytes (MON) were obtained using an automatic veterinary blood analyser (Exigo, Boule Medical AB, Sweden).

\section{CDs and WC4 antigens}

The percentages of peripheral blood lymphocytes such as T-cell $\left(\mathrm{CD}^{+}\right)$, T-helper cell $\left(\mathrm{CD}^{+}, \mathrm{Th}\right), \mathrm{T}$-cytotoxic suppressor cell $\left(\mathrm{CD}^{+}, \mathrm{Tc} / \mathrm{s}\right)$ and $\mathrm{B}$-cell $\left(\mathrm{WC4}^{+}\right)$antigens were determined using a flow cytometer (Coulter Epics XL 4C, Beckman Coulter Company, USA). The expression of the CD markers was determined using primary mouse anti-bovine monoclonal antibodies and for $\mathrm{WC4}^{+}$ expression additionally by the use of rabbit anti-mouse secondary polyclonal antibody (AbD Serotec, a Bio-Rad Company) as described by Dudek et al. (2015).

\section{Acute phase protein, $I L-4$ and IFN- $\gamma$ concentrations}

Commercial kits were used to determine acute phase proteins (APPs): haptoglobin (Hp) and serum amyloid A (SAA) (Tridelta Development Limited, Ireland) and the cytokines interferon-gamma (IFN- $\gamma$, ID.vet Innovative Diagnostics, France) and interleukin-4 (IL-4, USCN Life Science, Inc., Houston, USA).

Acute phase protein and cytokine concentrations, M. bovis antigen and specific antibodies to M. bovis, BHV1, BVDV, BRSV and PI3V were determined according to the individual ELISA procedures using an automated plate reader (Elx800 Microplate Reader, BioTek Instruments, Inc., USA). 


\section{IL-6, TNF- $\alpha, I L-10$ and IL-12 concentrations}

Directly before analysis samples were defrosted at $4{ }^{\circ} \mathrm{C}$ and then diluted 1:5 in PBS pH 7.0 (Sigma-Aldrich), as previously optimised. Six populations of microbeads (BD Biosciences) with distinctive fluorescence coated with monoclonal antibody for IL-6, TNF- $\alpha$, IL-10, IL-12(p40) and IL-12(p70) were used during cytometric analysis. Standards for the examined cytokines (BD Bioscience) were prepared according to the manufacturer's instruction. To $50 \mu \mathrm{l}$ of microbeads mix (diluted 1:50; BD Biosciences) $50 \mu \mathrm{l}$ of each sample was added, incubated at $18-25^{\circ} \mathrm{C}$ for $1 \mathrm{~h}$. Then $50 \mu \mathrm{l}$ of the detection mix (antibodies conjugated with PE, diluted 1:50, BD Biosciences) was added and incubated for $2 \mathrm{~h}$ in the dark. Microbeads were washed with $1 \mathrm{ml}$ of PBS pH 7.0 (Sigma-Aldrich), centrifuged at $300 \mathrm{~g}$ for $10 \mathrm{~min}$ and suspended in $300 \mu \mathrm{l}$ of PBS. The samples were analysed using a flow cytometer (Navios, Beckman Coulter Company, USA) at $576 \mathrm{~nm}(\mathrm{PE}), 660 \mathrm{~nm}(\mathrm{APC})$ and $680 \mathrm{~nm}(\mathrm{APC} / \mathrm{Cy} 7)$. The cytokine concentrations were calculated on the basis of standard curves. The final results were given in $\mathrm{pg} / \mathrm{ml}$ after calculating the dilution factor.

\section{Statistical analysis}

Arithmetic means \pm standard deviation were calculated with differences between the mean values of the groups at the same time point, and analysed using the $t$ test with a $\mathrm{P}<0.05$ level of statistical significance.

\section{Results}

The vaccine formulations had no bacterial contamination and no mycoplasma or Pasteurellaceae species were isolated from any of the nasal swabs of calves. No seroconversion to the respiratory viruses BHV-1, BVDV, BRSV and PI3V was observed.

\section{Clinical observations}

At day one post injection of the vaccine formulations the rectal temperature of all the calves was above the normal range $\left(40.4-41.1^{\circ} \mathrm{C}\right)$. By day 2 just two calves in the $\mathrm{S}+\mathrm{E}$ group and one calf in each of the $\mathrm{S}$ and $\mathrm{S}+\mathrm{E}+\mathrm{T}$ group had an elevated temperature. At days 3 and 4 the same calf in each of the $\mathrm{S}+\mathrm{E}$ and $\mathrm{S}+\mathrm{E}+\mathrm{T}$ groups had an elevated temperature. At day 5 only the $\mathrm{S}+\mathrm{E}$ calf had a slightly raised temperature but it was below $40.0^{\circ} \mathrm{C}$. Otherwise the animals' body temperatures, including those of the group $\mathrm{C}$ calves, were within the normal range $\left(37.5-39.5^{\circ} \mathrm{C}\right)$ throughout the study. 
One calf from the $\mathrm{S}+\mathrm{E}+\mathrm{T}$ group had a mucous nasal discharge at day 6 . A slight oedema at the site of injection was seen in some calves for a few weeks from day one post vaccination.

\section{Anti-M. bovis antibodies}

Specific $M$. bovis antibodies first appeared at day 7 and were raised until week 24 in all of the vaccinated calves, with the controls remaining negative. The S+E+T group had the highest percent (\%) at week 9; however, the titre of the $\mathrm{S}+\mathrm{E}$ group persisted at a higher level throughout the experiment (Fig. 1).

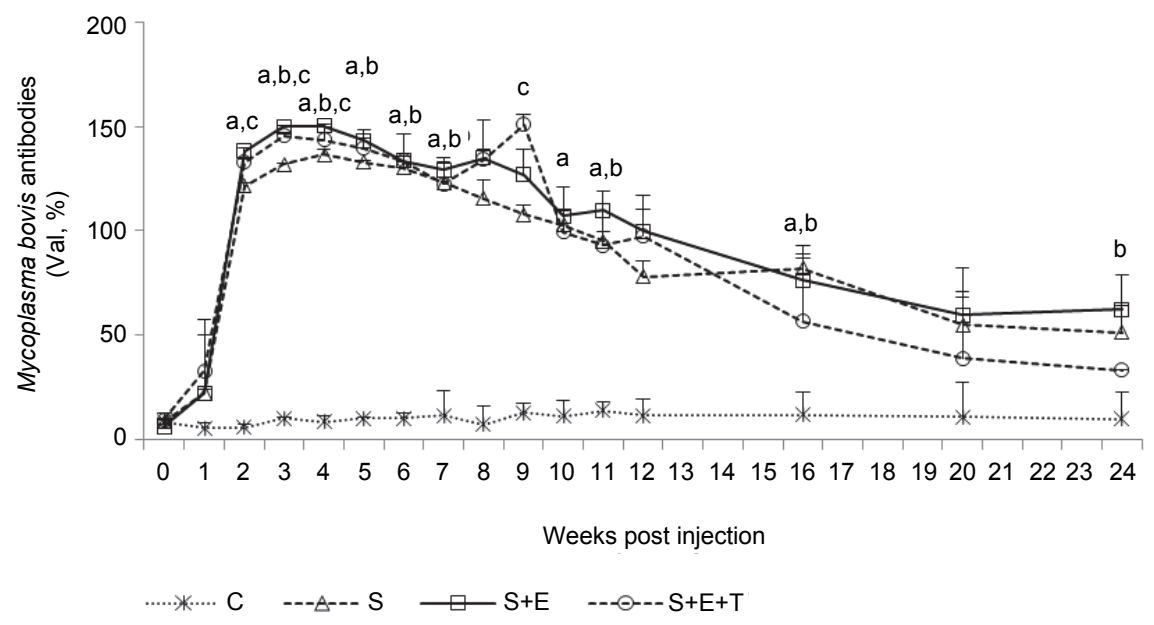

Fig. 1. Anti-Mycoplasma bovis specific antibodies of calves vaccinated with the M. bovis strain combined with either: saponin (S), saponin + Emulsigen $^{\mathbb{B}}\left(\mathrm{S}+\mathrm{E}\right.$, ) saponin + Emulsigen $^{\mathbb{B}}+$ alphatocopherol acetate $(\mathrm{S}+\mathrm{E}+\mathrm{T})$. a: significant differences at $\mathrm{P}<0.05$ between Groups $\mathrm{C}$ and $\mathrm{S}$; b: between Groups $\mathrm{C}$ and $\mathrm{S}+\mathrm{E}$; c: between Groups $\mathrm{C}$ and $\mathrm{S}+\mathrm{E}+\mathrm{T}$. Val, \%: value expressed in percentage, obtained by dividing the signal read (OD) for the sample by the signal read (OD) for the positive control serum and multiplying the result by 100. A sample is considered positive if the Val is higher than $37 \%$

\section{Blood leukocyte counts}

For all of the vaccine formulations, the WBC (Fig. 2a), GRA (Fig. 2b) and MID (Fig. 2d) counts increased compared to the control group at day 1 post injection. These counts then fell for all the experimental groups, giving comparable or lower values than the controls for most study days. The most evident GRA rise was observed in the $\mathrm{S}+\mathrm{E}+\mathrm{T}$ group.

The LYM count in the S group had comparable values to the control throughout the study, whereas in the other groups it was lower than the control for most study days (Fig. 2c). 


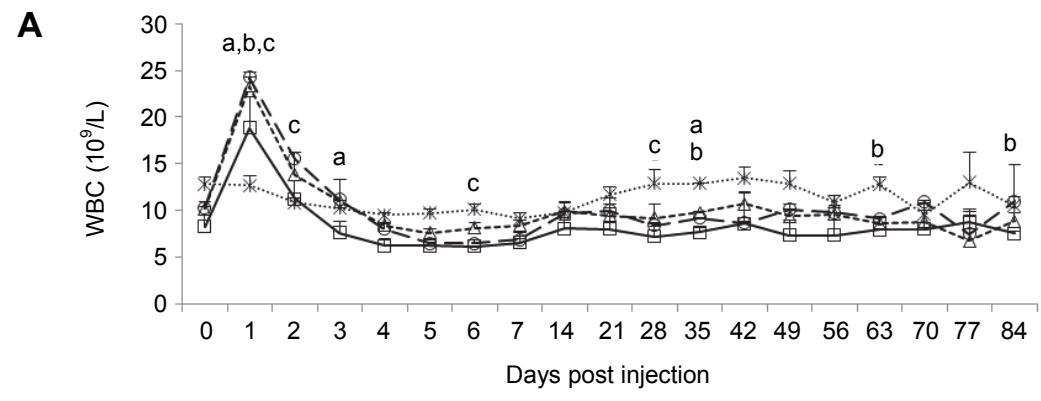

B

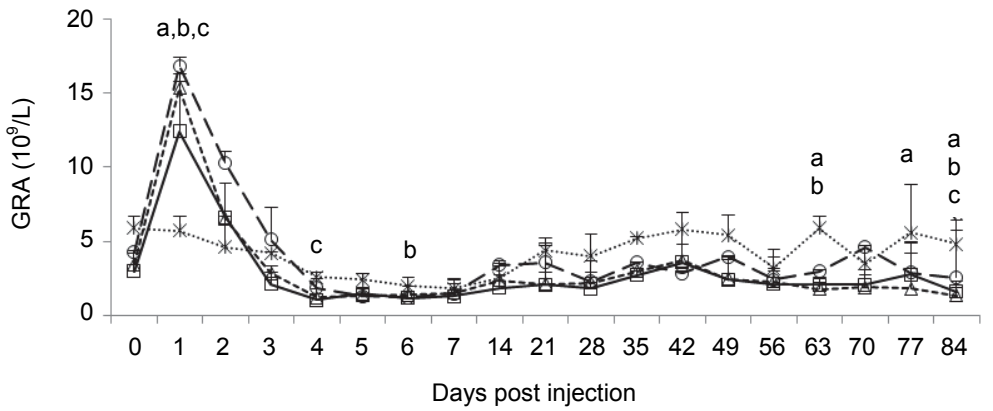

C

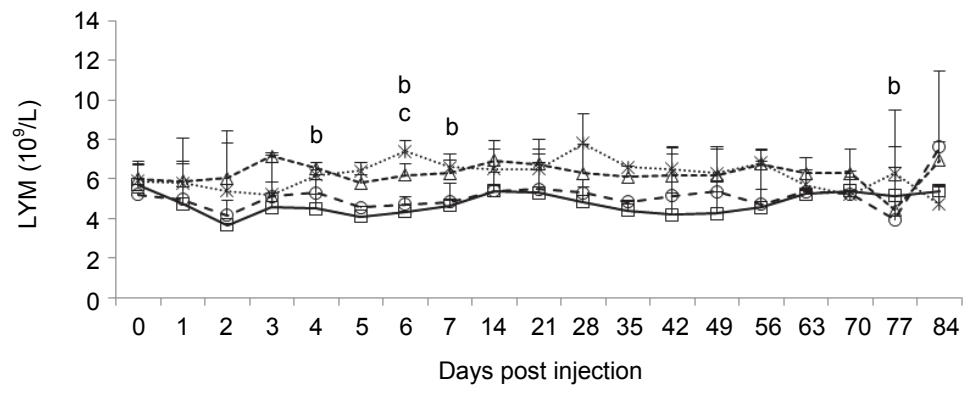

D

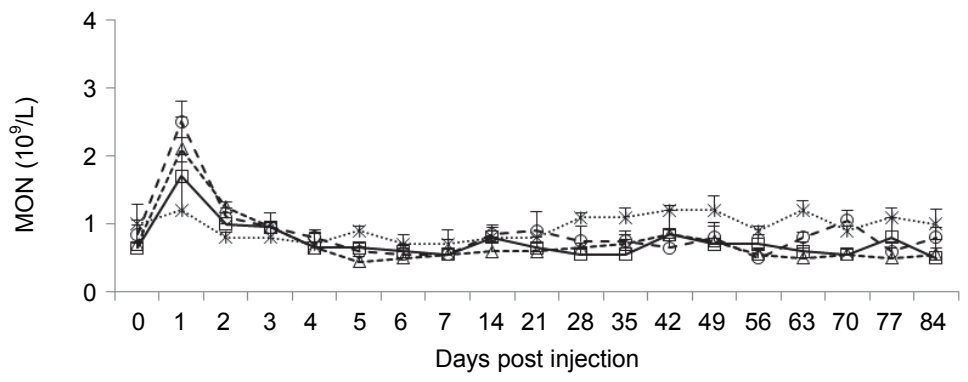

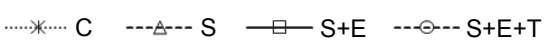

Fig. 2. Total white blood cell (WBC) count (2A) and WBC counts with differentiation of polymorphonuclear leukocytes (GRA, 2B), lymphocytes (LYM, 2C) and monocytes (MON, 2D) of calves vaccinated with the Mycoplasma bovis strain combined with either: saponin (S), saponin + Emulsi-

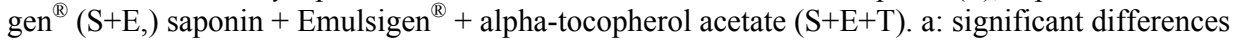
at $\mathrm{P}<0.05$ between Groups $\mathrm{C}$ and $\mathrm{S}$; b: between Groups $\mathrm{C}$ and $\mathrm{S}+\mathrm{E}$; $\mathrm{c}$ : between Groups $\mathrm{C}$ and $\mathrm{S}+\mathrm{E}+\mathrm{T}$ 


\section{CDs and WC4 antigens}

Throughout most of the study the $\mathrm{CD} 2^{+}$(Fig. 3a), CD4 $4^{+}$(Fig. 3b) and $\mathrm{CD}^{+}$(Fig. 3c) percent increase was most evident in the $\mathrm{S}+\mathrm{E}$ group compared to the controls, whereas the values of the other groups were comparable to the controls, with the exception of day 6 for $\mathrm{CD}^{+}$when a significant rise was observed in the $\mathrm{S}+\mathrm{E}+\mathrm{T}$ group.

The $\mathrm{WC4}^{+}$percent was stimulated earliest in the $\mathrm{S}$ group compared to the control; however, it was higher than the control in both the $\mathrm{S}$ and $\mathrm{S}+\mathrm{E}$ groups between days 5 and 35 post injection. This stimulation was prolonged in the $\mathrm{S}+\mathrm{E}$ group until day 49 . In the $\mathrm{S}+\mathrm{E}+\mathrm{T}$ group this percent was increased compared to the control between days 14 and 21, and also at days 35 and 49 post injection. However, the $\mathrm{WC}^{+}$percent was higher in all of the experimental groups than in the control between days 77 and 84 (Fig. 3d).

\section{Hp, SAA, IFN- $\gamma$ and IL-4 concentrations}

The Hp concentration was increased in all of the vaccinated groups. However, this rise was most evident in the $\mathrm{S}+\mathrm{E}+\mathrm{T}$ group until day 5 (Fig. 4a). The SAA concentration was increased in all the vaccinated groups until day 7 post injection. It was most evident in the $S$ group at day 1 and more visible in the $S+E$ and $\mathrm{S}+\mathrm{E}+\mathrm{T}$ groups at day 2 with the $\mathrm{S}+\mathrm{E}$ group peaking again at days 14 and 42 (Fig. 4b). The IFN- $\gamma$ concentration increased in all of the vaccinated groups until day 3 and then at days 4 and 7 in the $\mathrm{S}+\mathrm{E}$ and $\mathrm{S}+\mathrm{E}+\mathrm{T}$ groups, and additionally in the $\mathrm{S}+\mathrm{E}$ group at day 56 and for all vaccinated groups at day 77 (Fig. 4c).

The IL-4 concentration was increased in the S+E+T group at days 14 and 21 , whereas in the $\mathrm{S}+\mathrm{E}$ group it was higher than in the control group at days 7 , 21, 63 and 70. Throughout the study the values of the $\mathrm{S}$ group were comparable to those of the control group (Fig. 4d).

\section{IL-6, TNF- $\alpha, I L-10$ and IL-12 concentrations}

The IL-6 concentration was increased in the S+E group throughout the study. In the $\mathrm{S}$ and $\mathrm{S}+\mathrm{E}+\mathrm{T}$ groups it was comparable to the control with the exception of day 84 when a significant drop in the IL- 6 concentration was observed (Fig. 5a). The TNF- $\alpha$ and IL-10 concentrations in all of the vaccinated groups were comparable to the controls with the exception of day 56 when a TNF- $\alpha$ increase was observed especially in the S+E group (Fig. 5b) and an IL-10 decrease in the S group (Fig. 5c). The IL-12p70 concentration in the S group was comparable to that in the controls. In the other vaccinated groups it was higher than in the controls throughout the study; however, this rise was most evident in the S+E group (Fig. 5d). The IL-12p40 concentration in all of the vaccinated groups was comparable to the controls, with the exception of day 28 in the S+E group and day 56 in the $\mathrm{S}$ group when a visible rise was observed (Fig. 5e). 
A

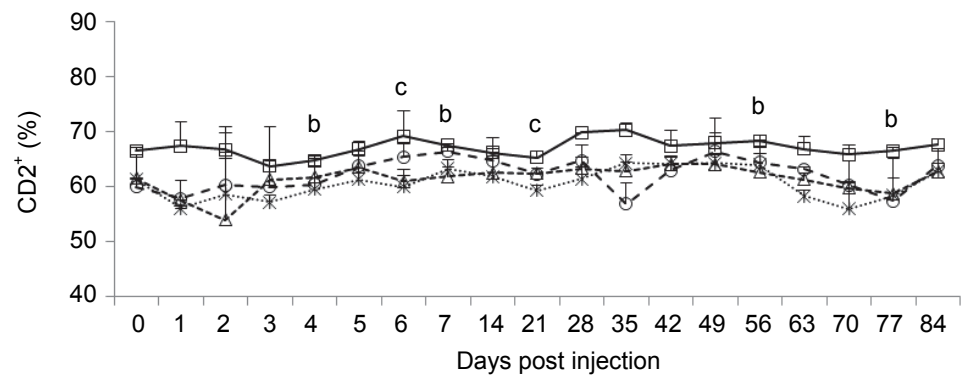

B

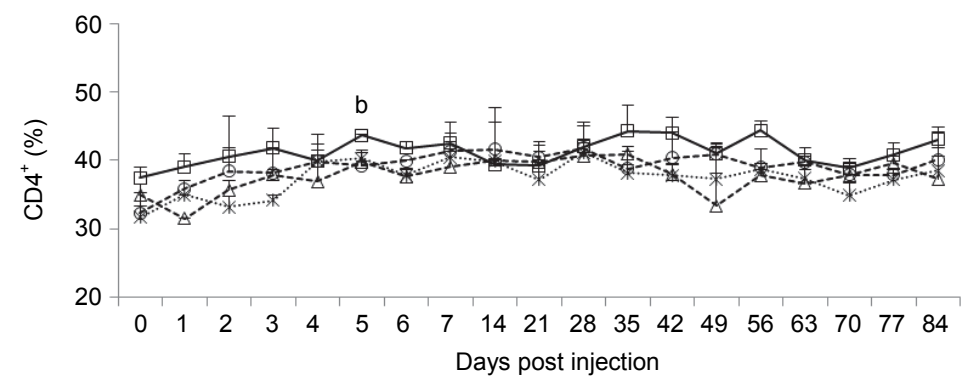

C

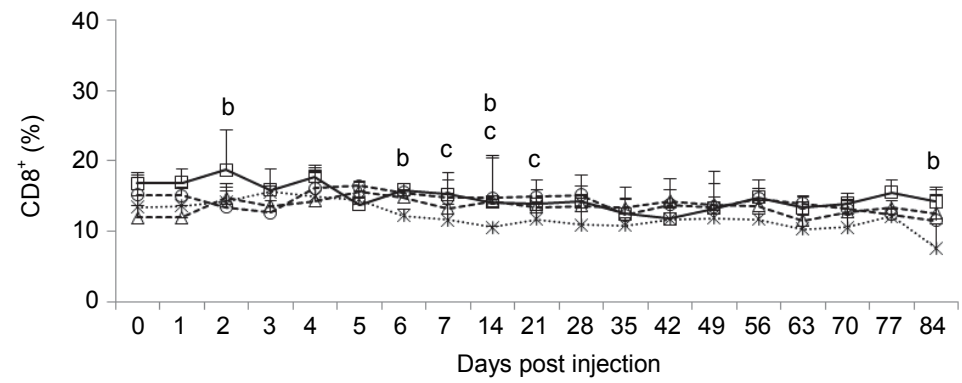

\section{D}

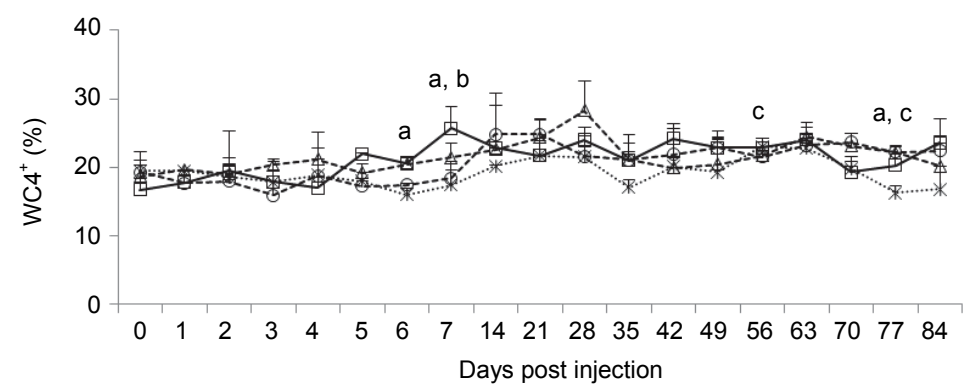

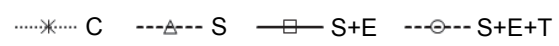

Fig. 3. $\mathrm{CD}^{+}(3 \mathrm{~A}), \mathrm{CD}^{+}(3 \mathrm{~B}), \mathrm{CD}^{+}(3 \mathrm{C})$ and $\mathrm{WC}^{+}(3 \mathrm{D})$ percentages of calves vaccinated with the Mycoplasma bovis strain combined with either: saponin (S), saponin + Emulsigen ${ }^{\mathbb{B}}(\mathrm{S}+\mathrm{E}$,) saponin + Emulsigen $^{\circledR}+$ alpha-tocopherol acetate $(\mathrm{S}+\mathrm{E}+\mathrm{T})$. a: significant differences at $\mathrm{P}<0.05$ between Groups $\mathrm{C}$ and $\mathrm{S}$; b: between Groups $\mathrm{C}$ and $\mathrm{S}+\mathrm{E}$; c: between Groups $\mathrm{C}$ and $\mathrm{S}+\mathrm{E}+\mathrm{T}$ 
A

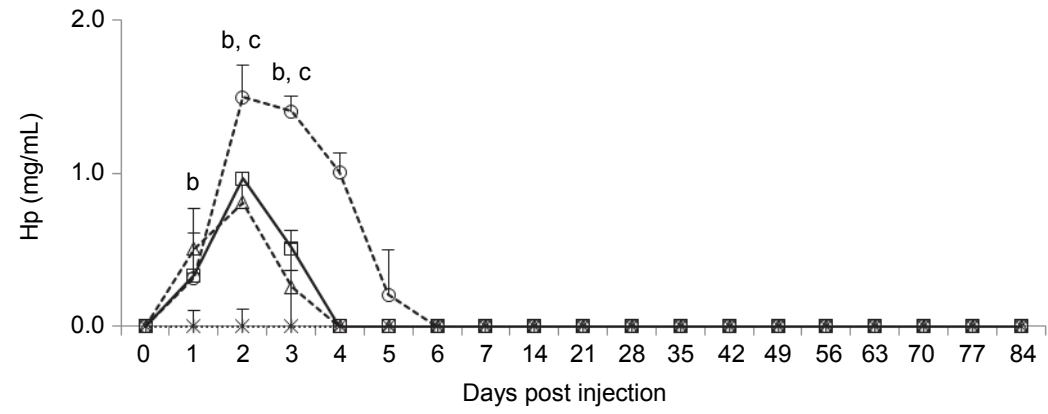

B

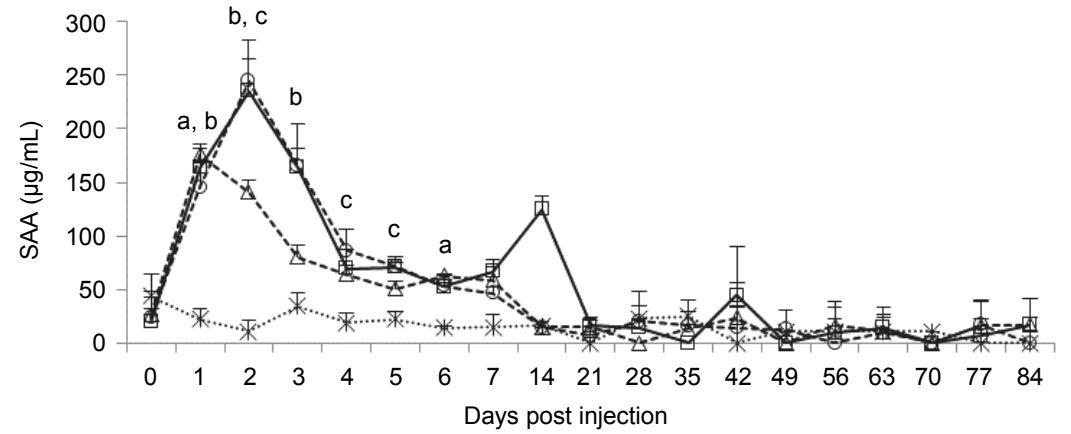

C

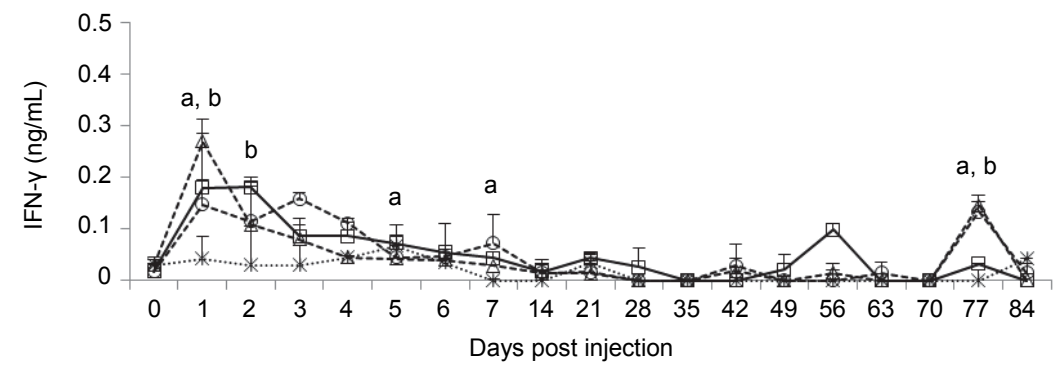

D

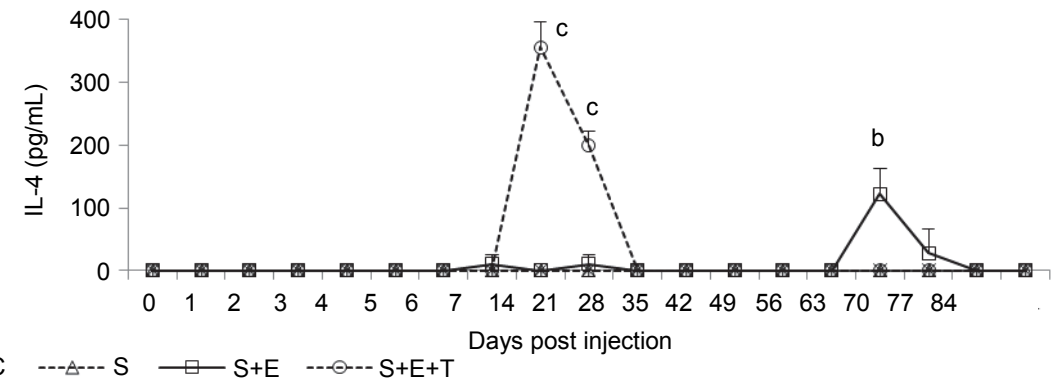

Fig. 4. Haptoglobin (Hp, 4A), serum amyloid A (SAA, 4B), interferon-gamma (IFN- $\gamma, 4 \mathrm{C})$ and interleukin-4 (IL-4, 4D) concentrations of calves vaccinated with the Mycoplasma bovis strain combined with either: saponin $(S)$, saponin + Emulsigen $^{\circledR}(\mathrm{S}+\mathrm{E}$, $)$ saponin + Emulsigen ${ }^{\circledR}+$ alphatocopherol acetate $(\mathrm{S}+\mathrm{E}+\mathrm{T})$. a: significant differences at $\mathrm{P}<0.05$ between Groups $\mathrm{C}$ and $\mathrm{S}$; b: between Groups $\mathrm{C}$ and $\mathrm{S}+\mathrm{E}$; c: between Groups $\mathrm{C}$ and $\mathrm{S}+\mathrm{E}+\mathrm{T}$ 
A

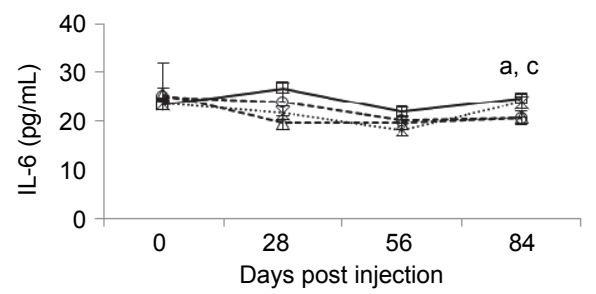

C

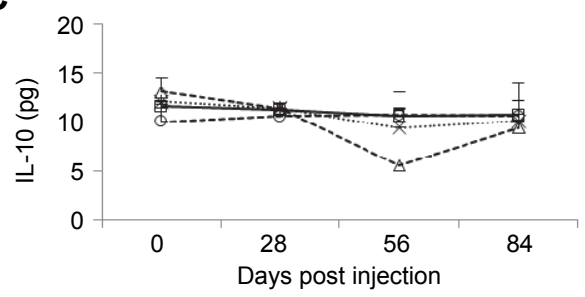

B

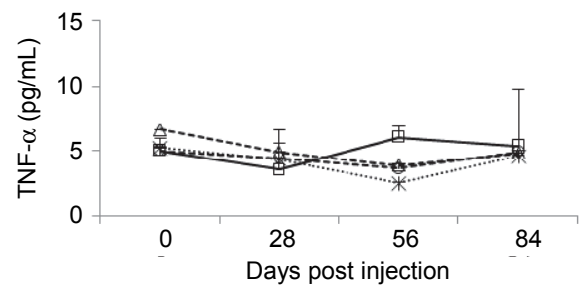

D

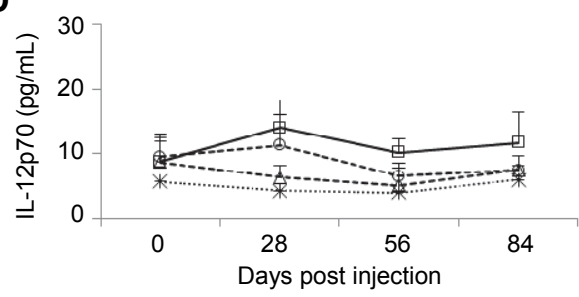

E

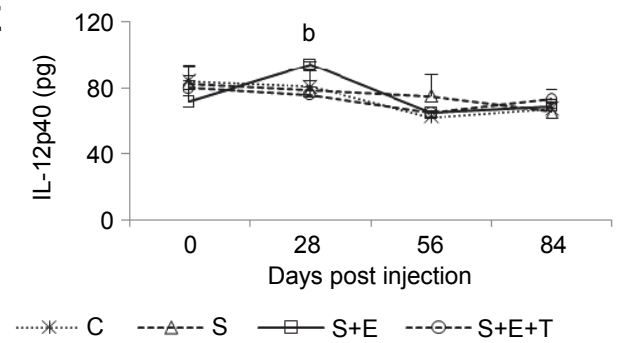

Fig. 5. IL-6 (5A), tumour necrosis factor-alpha (TNF- $\alpha, 5 B)$, IL-10 (5C), IL-12p70 (5D) and IL$12 \mathrm{p} 40$ (5E) concentrations of calves vaccinated with the Mycoplasma bovis strain combined with either: saponin (S), saponin + Emulsigen $^{\circledR}\left(\mathrm{S}+\mathrm{E}\right.$,) saponin + Emulsigen $^{\circledR}+$ alpha-tocopherol acetate $(\mathrm{S}+\mathrm{E}+\mathrm{T})$. a: significant differences at $\mathrm{P}<0.05$ between Groups $\mathrm{C}$ and $\mathrm{S}$; b: between Groups $\mathrm{C}$ and $\mathrm{S}+\mathrm{E}$; c: between Groups $\mathrm{C}$ and $\mathrm{S}+\mathrm{E}+\mathrm{T}$

\section{Discussion}

In this study, the stimulation of the systemic humoral immune response following the injection of different saponin-based adjuvant formulations combined with the field $M$. bovis strain was observed. All of the tested formulations effectively stimulated the production of specific antibodies to M. bovis which was observed from week 2 post injection. This stimulation lasted until week 24, which is consistent with the findings of our previous study (Dudek et al., 2016). A correlation between the stimulation of humoral immunity and the protective effect of saponin-adjuvanted bacterin vaccines was reported previously (Nicholas et al., 2002; Dudek et al., 2016). 
Considering the divergent opinions about the role of the humoral response in preventing $M$. bovis infections it is suggested that the cellular immunity is likely to be more effective in eliminating $M$. bovis from the host than the humoral response (Nicholas et al., 2017). In this study all of the tested saponin-based adjuvants appeared to enhance the cell-mediated immune response but this depended on the adjuvant formulation. The leukocytosis visible on day 1 post injection for all of the tested adjuvant formulations was probably the result of mobilisation of the blood immune cells, whereas general lymphopenia observed for most days of the study resulted from lymphocyte recirculation. The stimulation of the T-cell response following the injection of all of the tested saponin adjuvants was reflected in the increase of both the Th and T c/s cells. However, the most evident Th cell response was observed in the $\mathrm{S}+\mathrm{E}$ group, whereas a stronger stimulation of $\mathrm{Tc} / \mathrm{s}$ cells was shown in the remaining experimental groups. It is known that cytokines secreted by Th lymphocytes play a role in the differentiation of B lymphocytes into the pool of plasmatic cells secreting antibodies (Hermeyer et al., 2012). In this study the most evident B-cell response and the strongest stimulation of the $M$. bovis-specific antibodies were in the $\mathrm{S}+\mathrm{E}$ group. A general stimulation of the $\mathrm{CD}^{+}$and $\mathrm{WC}^{+}$cells to an M. bovis infection was indicated previously, regardless of the isolate used as a challenge (Dudek et al., 2015). Vanden Bush and Rosenbusch (2003) demonstrated that the recall immune response to $M$. bovis is skewed towards a Th2 response which resulted from a dominant IL-4 response. The activation of both the $\mathrm{CD} 4^{+}$and $\mathrm{CD} 8^{+}$cells was also reported (Vanden Bush and Rosenbusch, 2003). It is known that IL-4 plays an important role in B-cell differentiation (Estes et al., 1995). In contrast to the Th2 response, the Th1 response is characterised by an increase in IFN- $\gamma$ with no IL-4 response (Estes et al., 1995; Vanden Bush and Rosenbusch, 2003). In another study, significant stimulation of IFN- $\gamma$ concentration was observed with all of the saponin-based adjuvant formulations. In that study the IL-4 response was poor and observed on just a few days which may suggest that the immune response to saponin-based $M$. bovis vaccine is characterised by a Th1-skewed cytokine production or it is a slightly mixed Th-1-Th-2 cytokine response. This hypothesis could also be confirmed by a lack of significant changes in the concentration of IL-10, one of the cytokines associated with the Th2 response, following immunisation with all of the saponin-based adjuvants (O'garra and Vieira, 2004; Saraiva and O'Garra, 2010). In contrast, specifically in the S+E group, a stimulation of the production of IL-12, i.e. of the cytokine which is crucial for the induction of the Th1 response, was recorded (Farias et al., 2016). In this study a stimulation of IL- 6 and TNF- $\alpha$ production was observed in all of the vaccinated groups, but the response varied with the different adjuvant formulations. However, the most evident cytokine stimulation was recorded in the S+E group. IL- 6 and TNF- $\alpha$ are known to be pro-inflammatory cytokines. It was previously reported that TNF- $\alpha$ and IFN- $\gamma$ are key cytokines for the induction of other cyto- 
kines, e.g. IL-6 (van Miert, 1995). Whilst IL-6 is responsible for depressing TNF- $\alpha$ production, it also has an antagonistic effect on IL-10 with regard to IL-6 production (Schindler et al., 1990; Knolle et al., 1995). However, an increased IL- 6 and TNF- $\alpha$ concentration observed previously stabilised in all of the vaccinated groups on day 84 . In comparison, the two commercially available $M$. bovis bacterin vaccines did not have a significant effect on the serum concentrations of the screened cytokines including IL- $1 \beta$, IL-2, IL-4, IL- 6 , IFN- $\gamma$ or TNF$\alpha$ (Soehnlen et al., 2011). However, Zhang et al. (2014) showed that in response to two live attenuated $M$. bovis vaccines TNF- $\alpha$ levels were not detectable. Further studies using wider cytokine profiles are required to increase our understanding of these interrelated responses.

Previously Dudek et al. $(2011 a, 2013)$ reported that $M$. bovis activated the acute phase response (APR) and the saponin-based adjuvant formulations effectively stimulated Hp and SAA production. Some cytokines, including IL-6 and TNF- $\alpha$, act as mediators of the production of APPs during APR (Heinrich et al., 1990; Gruys et al., 2005). The increased IL-6 production observed in the S+E group at the beginning of the study may have been responsible for stimulating the concentration of the examined APPs. Hp and SAA are known as major bovine APPs and were previously recognised as effective indicators of bovine health and disease (Ceciliani et al., 2012). It is known that human SAA has chemotactic activity towards polymorphonuclear leukocytes and monocytes but this function is still under investigation in cattle (Badolato et al., 1994). The few days of increased SAA concentration could be associated with leukocyte recruitment and further their migration, adhesion and infiltration of target tissues, as has been described in a human model (Badolato et al., 1994). Modulating the immunological functions of leukocytes facilitates avoidance of the host's immune system. Mycoplasma bovis can inhibit the bovine neutrophil respiratory burst, which is known to be a major antimicrobial mechanism associated with the production of reactive oxygen species (ROS) (Thomas et al., 1991; Fang, 2004). A reported function of SAA is the inhibition of oxidative burst response in human neutrophils and that the SAA counteracts responses of these cells to cytokines or bacteria, which may prevent oxidative destruction of the tissues by ROS (Linke et al., 1991). Therefore, the observed initial stimulation of SAA concentration supports a beneficial effect of the tested vaccines.

Mycoplasma bovis is able to cause inflammation within various bovine organs (Nicholas and Ayling, 2003). An infection with these bacteria may lead to the activation of alveolar macrophages resulting in neutrophil migration to the targeted tissues and release of proinflammatory mediators (Maunsell et al., 2011). Mycoplasma bovis may activate the synthesis of some arachidonic acid metabolites (Dudek et al., 2011b). Haptoglobin is also known to inhibit the respiratory burst activity of human neutrophils as a result of stimulation of diverse agonists, e.g. arachidonic acid (Oh et al., 1990). Considering these anti-inflammatory ac- 
tivities of $\mathrm{Hp}$, its observed initial stimulation post injection appears to indicate a beneficial effect of the $M$. bovis strain and adjuvant combination.

All saponin-based formulations effectively stimulated the humoral and cellular immune response in the calves. This further supports the use of saponin and Emulsigen ${ }^{\circledR}$ as demonstrated successfully in a challenge study (Dudek et al., 2016).

\section{References}

Ayling, R. D., Baker, S. E., Peek, M. L., Simon, A. J. and Nicholas, R. A. J. (2000): Comparison of in vitro activity of danofloxacin, florfenicol, oxytetracycline, spectinomycin and tilmicosin against recent field isolates of Mycoplasma bovis. Vet. Rec. 146, 745-747.

Badolato, R., Wang, J. M., Murphy, W. J., Lloyd, A. R., Michiel, D. F., Bausserman, L. L., Kelvin, D. J. and Oppenheim, J. J. (1994): Serum amyloid A is a chemoattractant: induction of migration, adhesion, and tissue infiltration of monocytes and polymorphonuclear leukocytes. J. Exp. Med. 180, 203-209.

Barrow, G. I. and Feltham, R. K. A. (1993): Cowan and Steel's Manual for the Identification of Medical Bacteria. Cambridge University Press, Cambridge.

Ceciliani, F., Ceron, J. J., Eckersall, P. D. and Sauerwein, H. (2012): Acute phase proteins in ruminants. J. Proteomics 75, 4207-4231.

Dudek, K., Bednarek, D., Ayling, R. D., Kycko, A., Szacawa, E. and Karpińska, T. A. (2016): An experimental vaccine composed of two adjuvants gives protection against Mycoplasma bovis in calves. Vaccine 34, 3051-3058.

Dudek, K., Bednarek, D., Ayling, R. D. and Szacawa, E. (2013): Immunomodulatory effect of $M y$ coplasma bovis in experimentally infected calves. Bull. Vet. Inst. Pulawy 57, 499-506.

Dudek, K., Bednarek, D. and Szacawa, E. (2011a): Evaluation of immune response in seropositive cattle for Mycoplasma bovis. Bull. Vet. Inst. Pulawy 55, 631-634.

Dudek, K., Bednarek, D. and Szacawa, E. (2011b): Stimulating effect of Mycoplasma bovis infection on proinflammatory response in infected cattle. Bull. Vet. Inst. Pulawy 55, 599-602.

Dudek, K., Bednarek, D., Szacawa, E., Rosales, R. S. and Ayling, R. D. (2015): Flow cytometry follow-up analysis of peripheral blood leukocyte subpopulations in calves experimentally infected with field isolates of Mycoplasma bovis. Acta Vet. Hung. 63, 167-178.

Estes, D. M., Hirano, A., Heussler, V. T., Dobbelaere, D. A. E. and Brown, W. C. (1995): Expression and biological activities of bovine interleukin 4: effects of recombinant bovine interleukin 4 on $\mathrm{T}$ cell proliferation and $\mathrm{B}$ cell differentiation and proliferation in vitro. Cell. Immunol. 163, 268-279.

Fang, F. C. (2004): Antimicrobial reactive oxygen and nitrogen species: concepts and controversies. Nat. Rev. Microbiol. 2, 820-832.

Farias, M. V. N., Lendez, P. A., Marin, M., Quintana, S., Martínez-Cuesta, L., Ceriani, M. C. and Dolcini, G. L. (2016): Toll-like receptors, IFN- $\gamma$ and IL-12 expression in bovine leukemia virus-infected animals with low or high proviral load. Res. Vet. Sci. 107, 190-195.

Gruys, E., Toussaint, M. J., Niewold, T. A. and Koopmans, S. J. (2005): Acute phase reaction and acute phase proteins. J. Zhejiang Univ. Sci. B. 6, 1045-1056.

Heinrich, P. C., Castell, J. V. and Andus, T. (1990): Interleukin-6 and the acute phase response. Biochem. J. 265, 621-636.

Hermeyer, K., Buchenau, I., Thomasmeyer, A., Baum, B., Spergser, J., Rosengarten, R. and Hewicker-Trautwein, M. (2012): Chronic pneumonia in calves after experimental infection with Mycoplasma bovis strain 1067: Characterization of lung pathology, persistence of variable surface protein antigens and local immune response Acta Vet. Scand. 54, 9. 
Knolle, P., Löhr, H., Treichel, U., Dienes, H. P., Lohse, A., Schlaack, J. and Gerken, G. (1995): Parenchymal and nonparenchymal liver cells and their interaction in the local immune response. Z. Gastroenterol. 33, 613-620.

Linke, R. P., Bock, V., Valet, G. and Rothe, G. (1991): Inhibition of the oxidative burst response of $\mathrm{N}$-formyl peptide-stimulated neutrophils by serum amyloid-A protein. Biochem. Biophys. Res. Commun. 176, 1100-1105.

Maunsell, F. P., Donovan, G. A., Risco, C. and Brown, M. B. (2009): Field evaluation of a Mycoplasma bovis bacterin in young dairy calves. Vaccine $27,2781-2788$.

Maunsell, F. P., Woolums, A. R., Francoz, D., Rosenbusch, R. F., Step, D. L., Wilson, D. J. and Janzen, E. D. (2011): Mycoplasma bovis infections in cattle. J. Vet. Intern. Med. 25, 772-783.

Nicholas, R. A. J. and Ayling, R. D. (2003): Mycoplasma bovis: disease, diagnosis and control. Res. Vet. Sci. 74, 105-112.

Nicholas, R. A. J. and Baker, S. E. (1998): Recovery of mycoplasmas from animals. In: Miles, R. J. and Nicholas, R. A. J. (eds) Mycoplasma Protocols. Humana Press, Totowa. pp. 37-44.

Nicholas, R. A. J., Ayling, R. D. and Stipkovits, L. P. (2002): An experimental vaccine for calf pneumonia caused by Mycoplasma bovis: clinical, cultural, serological and pathological findings. Vaccine 20, 3569-3575.

Nicholas, R. A. J., Rosales, R. S. and Loria, G. R. (2017): Mycoplasmology: the big issues. AHDVS 1, 1-4.

O'garra, A. and Vieira, P. (2004): Regulatory T cells and mechanisms of immune system control. Nat. Med. 10, 801-805.

Oh, S. K., Pavlotsky, N. and Tauber, A. I. (1990): Specific binding of haptoglobin to human neutrophils and its functional consequences J. Leukoc. Biol. 47, 142-148.

Postgate, J. R. (1969): Viable counts and viability. In: Norris, J. R. and Ribbons, D. W. (eds) Methods in Microbiology, Academic Press Inc., New York. pp. 611-628.

Saraiva, M. and O'Garra, A. (2010): The regulation of IL-10 production by immune cells. Nat. Rev. Immunol. 10, 170-181.

Schindler, R., Mancilla, J., Endres, S., Ghorbani, R., Clark, S. C. and Dinarello, C. A. (1990): Correlations and interactions in the production of interleukin-6 (IL-6), IL-1, and tumor necrosis factor (TNF) in human blood mononuclear cells: IL-6 suppresses IL-1 and TNF. Blood 75, $40-47$.

Soehnlen, M. K., Aydin, A., Lengerich, E. J., Houser, B. A., Fenton, G. D., Lysczek, H. R., Burns, C. M., Byler, L. I., Hattel, A. L., Wolfgang, D. R. and Jayarao, B. M. (2011): Blinded, controlled field trial of two commercially available Mycoplasma bovis bacterin vaccines in veal calves. Vaccine 29, 5347-5354.

Szacawa, E., Niemczuk, K., Dudek, K., Bednarek, D., Rosales, R. and Ayling, R. (2015): Mycoplasma bovis infections and co-infections with other Mycoplasma spp. with different clinical manifestations in affected cattle herds in eastern region of Poland. Bull. Vet. Inst. Pulawy 59, 331-337.

Thomas, C. B., Van Ess, P., Wolfgram, L. J., Riebe, J., Sharp, P. and Schultz, R. D. (1991): Adherence to bovine neutrophils and suppression of neutrophil chemiluminescence by Mycoplasma bovis. Vet. Immunol. Immunopathol. 27, 365-381.

van Miert, A. S. (1995): Pro-inflammatory cytokines in a ruminant model: pathophysiological, pharmacological, and therapeutic aspects. Vet. Q. 17, 41-50.

Vanden Bush, T. J. and Rosenbusch, R. F. (2003): Characterization of the immune response to $M y$ coplasma bovis lung infection. Vet. Immunol. Immunopathol. 94, 23-33.

Zhang, R., Han, X., Chen, Y., Mustafa, R., Qi, J., Chen, X., Hu, C., Chen, H. and Guo, A. (2014): Attenuated Mycoplasma bovis strains provide protection against virulent infection in calves. Vaccine 32, 3107-3114. 